\title{
Reconstrucción de memoria y propuesta pedagógica en el municipio de Toca (Boyacá, Colombia). Del desarrollo al Posdesarrollo Rural
}

\section{Reconstruction and pedagogical memory in Toca town (Boyacá, Colombia). From Development to the Rural Post-Development}

\author{
José Manuel Alba Maldonado ${ }^{1}$, y Andrea Carolina García Cabana ${ }^{2}$ \\ IIngeniero Agrónomo, Magister en Desarrollo Rural. ${ }^{2}$ Ingeniera Forestal, Magister en Desarrollo Rural \\ Universidad Nacional Abierta y a Distancia (UNAD). Escuela de Ciencias de la Educación (ECEDU). \\ CEAD Tunja. Colombia. ${ }^{2}$ Universidad Nacional Abierta y a Distancia (UNAD). Escuela de Ciencias \\ Agrícolas Pecuarias y del Medio Ambiente (ECAPMA). CEAD Tunja. Colombia.
}

1jose.alba@unad.edu.co, ${ }^{2}$ andrea.garcia@unad.edu.co

\begin{abstract}
Resumen
El siguiente artículo es resultado de la tesis de grado en la Maestría en Desarrollo Rural, Titulada "Posdesarrollo rural. Propuesta pedagógica de rescate de memoria en el municipio de TocaBoyacá". El artículo está dividido en tres partes, la primera se enfoca en la descripción sobre el problema y el objetivo, centrado en una crítica al desarrollo y mostrando cómo el posdesarrollo es un camino viable, teniendo como base la memoria colectiva en una propuesta pedagógica. En la segunda parte, se hace una breve descripción de la metodología de la investigación, ubicándola en un enfoque histórico hermenéutico, dentro de un método etnográfico en lo que respecta al rescate de memoria colectiva del Municipio y de investigación acción participativa en lo que respecta al trabajo con los estudiantes del Instituto Técnico Agrícola de Toca; en ésta parte también se hace una revisión bibliográfica sobre el concepto de posdesarrollo. En la última parte, se realiza una exposición de los resultados, dividida en dos secciones, en la primera se muestra, fruto del trabajo etnográfico, el rescate de la memoria, descubriendo sitios de
\end{abstract}

importancia histórico-cultural, cuentos folclóricos entre otros; la segunda parte, evidencia el trabajo con los estudiantes, su transformación en investigadores y el encuentro con la memoria, todo esto enmarcado en el proceso de cimentación del posdesarrollo.

Palabras claves: desarrollo rural, posdesarrollo, memoria

\section{Abstract}

The following article is the product of a master's thesis in Rural Development, entitled "Post-rural development. A pedagogical proposal for the recovery of memory in the municipality of Toca-Boyacá". The article is divided into three parts: the first focuses on describing the problem and the objective, and is centered on a critique of development while arguing for post-development as a viable route, based on the collective memory of a pedagogical proposal. The second part is a brief description of the methodology of the study, placing it in a historical hermeneutic focus using an ethnographic method that recovers 
the collective memory of the municipality, and participatory action research relating to students of the Instituto Técnico Agrícola de Toca. Furthermore, this part includes a literary review on the concept of post-development. The last part presents the results, divided into two sections, the first showing, the fruit of ethnographic investigation, the recovery of memory, discovery of historically and culturally important sites, and folktales among others. The second part presents the work of the students, their transformation into the role of researchers and their encounter with memory, all framed in the post-development process foundation.

Keywords: rural development, post-development, memory

\section{Introducción}

El artículo presenta una propuesta pedagógica que parte desde una crítica del desarrollo y sus impactos en el ámbito rural, como el incremento de la pobreza y la invasión cultural a la que se ven sometidas estas zonas. Desde esta problemática se plantea el concepto del "posdesarrollo", como un nuevo camino para enfrentar, las falencias de las políticas sociales y económicas que dejan a un lado lo local.

El mundo de hoy, y en especial el del sector rural, atraviesa un alto grado de desvinculación con el pasado, esto hace que las sociedades, desconozcan la historia, vivan en un presente inerte y conciban el futuro como un porvenir incierto. El desarrollo tiene un alto grado de responsabilidad en esto, ya que ha mostrado desde su discurso a algunas culturas y su pasado, como causas del atraso. Así se han desligado generaciones enteras de sus raíces culturales y su memoria. El posdesarrollo; sin embargo, plantea que es en la memoria y en la cultura, y no en una ruta economicista, donde emergen las esperanzas para la construcción de nuevas sociedades.

Sin duda alguna, la educación es el pilar para generar cambios importantes en una sociedad, es por esto que este trabajo de investigación, encaminó todo sus esfuerzos a crear vínculos entre la memoria colectiva del pueblo y los jóvenes del municipio de Toca, como una forma de crear nuevas formas de concebir sociedades y culturas, ya no desde la mirada productivista y economicista del desarrollo, sino desde la mirada que reconoce lo que se es desde la memoria, hacia una ruta de posdesarrollo.

\section{Objetivos}

Partiendo de esta problemática el objetivo del proyecto investigativo fue: reconocer en la memoria de pobladores del municipio de Toca mayores de 50 años, desde aspectos como cuentos folclóricos y leyendas e imaginarios relacionados con los sitios de importancia cultural, un pilar fundamental en la construcción de un posdesarrollo rural generador de identidad histórica y sentido de pertenencia en jóvenes del Instituto Técnico Agropecuario del municipio de Toca-Boyacá

Los objetivos específicos fueron:

Identificar cómo la memoria es un renovador del concepto del desarrollo y cómo partiendo de ésta, se puede llegar a plantear un posdesarrollo;

Realizar un rescate de memoria en pobladores del municipio de Toca mayores de 50 años, aspectos como cuentos folclóricos y leyendas e imaginarios relacionados con los sitios de importancia cultural y Reconocer la memoria como generador de identidad histórica y sentido de pertenencia en jóvenes del Instituto Técnico Agropecuario del municipio de Toca, como un pilar del posdesarrollo.

El posdesarrollo en este trabajo se articula con la memoria. 


\section{Historia del desarrollo}

La historia del Desarrollo se remonta según MaxNeef (1997), a los años 20 cuando Joseph Schumpenter, escribió los conceptos del desarrollo económico, en los tiempos de la gran depresión. Sin embargo en los años cincuenta tomó otro giro, cuando el presidente Harry Truman manifestó en su discurso de posesión:

"Lo que tenemos en mente es un programa de desarrollo basado en los conceptos de trato justo y democrático... Producir más es la clave para la paz y la prosperidad. Y la clave para producir más es una aplicación mayor y más vigorosa del conocimiento técnico y científico moderno" (Max-Neef, 1997).

Este discurso iba a marcar una nueva dinámica en el orden mundial, en donde se reinventarían las formas de dominación de los países del Norte frente a sus antiguas colonias. Desde este discurso se hace una relación de producción y paz; no obstante este producir estaba enmarcado dentro de laboratorios y empresas ubicadas en la base del poder: el Norte.

En esta época, amplios sectores de los países latinoamericanos lucharon por la construcción de la identidad nacional. Es así como el "discurso de desarrollo", nace como una nueva forma de control de los "países en desarrollo" (De Greiff, 2005).

Escobar señala que en 1951 un grupo de expertos congregados por Naciones Unidas, planteó frente al desarrollo de los países subdesarrollados:

"Hay un sentido en el que el progreso económico acelerado es imposible sin ajustes dolorosos. Las filosofías ancestrales deben ser erradicadas; las viejas instituciones sociales tienen que desintegrarse; los lazos de casta, credo y raza deben romperse... Muy pocas comunidades están dispuestas a pagar el precio del progreso económico" (Escobar, 1996).
El Desarrollo ha llevado a duros impactos en las culturas ancestrales, en las filosofías no occidentales y en las viejas instituciones sociales, ya que desde los discursos de progreso y civilización, el imaginario sobre las culturas tradicionales, se ha visto como una traba para la economía.

\section{Desarrollo rural}

Para Absalón Machado (2001), las políticas agrarias se enmarcan en dos modelos económicos, el proteccionismo que nace después de la segunda guerra y en donde las políticas tenían como eje central la industrialización, olvidándose de las ventajas comparativas que tenía el país en tierra, mano de obra y abandonando al campesino.

El modelo aperturista, por su parte, se da después de 1990, se centró en la producción de los productos que tengan ventajas competitivas, así se libera la protección y entra a regir el mercado. De esta forma, las empresas transnacionales penetran los mercados y toman el control de estos con precios muy bajos.

Ninguna de las políticas y medidas económicas, movidas por el discurso de Desarrollo, han tenido los resultados esperados, al contrario, para Machado (2001) los niveles de pobreza y exclusión no ceden, se desmontan programas y se disponen de menos recursos públicos.

El Desarrollo Rural, no ha cumplido su objetivo y, por otro lado, se ha llevado una invasión cultural al sector rural implantando una única idea de producción, social y económica.

\section{Invasión cultural}

Según Max-Neef (1984) en la mayor parte de los países del Tercer Mundo los estilos de desarrollo impuestos tienden a aumentar la marginalización de los campesinos. Así, mientras la clase dominante diseña su propia estrategia de desarrollo, se 
abandona a los sectores invisibles a que elaboren sus propias estrategias de supervivencia.

En esta dinámica, los países del primer mundo imponen el desarrollo, e invaden culturalmente desde su espacio histórico-cultural a los países subdesarrollados, obligándoseles a cambiar toda su historia y cultural. En los 70 fue la industrialización, hoy es la empresarización.

La principal deuda que tiene la sociedad con el campesinado, para Forero (2010), es reconocerlo como un productor, que contribuye sustancialmente a la alimentación, agroindustria y exportaciones del país. Y como un ciudadano que tiene plenos derechos activo y partícipe de la producción cultural del país.

Desde esta mirada del desarrollo se realizó un rastreo a nuevas posturas frente al desarrollo, concibiendo y reflexionando formas de pensar ese concepto que ha servido como motor en este tiempo.

\section{El posdesarrollo}

Arturo Escobar desde el pensamiento latinoamericano critica el desarrollo, y es el primero en plantear el "posdesarrollo". Sus argumentos se dirigen al fracaso del desarrollo para erradicar la pobreza, y devela como esté ha servido en el control político y económico por parte de los países desarrollados sobre los países subdesarrollados.

Desde su concepción más sencilla "el posdesarrollo se puede definir como un movimiento disidente intelectual y social, que ve en la economía y tecnociencia no el material para una irresponsable aventura más en desarrollo, sino la posibilidad de inventar nuevas formas de ser libre" (Escobar, 1996).

La cultura como forma de identidad marca el camino para el posdesarrollo, es decir, que en el encontrarnos con nosotros mismos, se edifica la construcción del futuro. Por eso, para Max-Neff (1997) el primer y desesperado esfuerzo ha de ser el de encontrarse con uno mismo y convencerse que el mejor desarrollo es el del país y la cultura capaz de ser coherentes consigo mismo.

Así, desde lo cultural surge la defensa de lo local, ya que es desde allí donde se fortalece la identidad lo que genera críticas a la propia situación. La identidad parte de la memoria, desde ella se edifica lo que se es, se echa raíz en el suelo, se empieza a construir el futuro teniendo en cuenta el presente y como brújula el pasado. Es desde la memoria donde la cultura cobra forma para encaminarse al posdesarrollo.

\section{No hay posdesarrollo sin memoria}

Siguiendo a Fontana (2006), la memoria colectiva, no es recuperar del pasado verdades enterradas, sino usar su capacidad de construir presente recordados para la formación de la clase de conciencia colectiva que corresponde a las necesidades del momento, creando escenarios en que es posible encajar e interpretar los hechos nuevos que se presentan, escenarios en que el pasado ilumina, cuando se presenta un momento histórico de peligro.

Así en el posdesarrollo el pasado se transforma en pasado vivificante que direcciona el presente y crea conciencia, enfrentando la invasión cultural del desarrollo. En este sentido, el posdesarrollo, teniendo como base la historia, busca el reconocimiento de la historicidad popular y el fortalecimiento de un imaginario que conduzca a su sentido de pertenencia social.

Pero este trabajo cobra sentido en la medida que se articula con procesos como el de la educación popular. Una educación popular que se construye, partiendo de un autoreconocimiento y un análisis de la sociedad, para plantear el inicio de su propio desarrollo. 
Aludiendo a Chavez (2010), la memoria o los recuerdos colectivos, ya sean públicos o privados, convierten a un pueblo, en un lugar en los que la vida se ha sedimentado, lo cual hace del lugar algo habitable; esto a su vez permite que se establezca una retroalimentación entre el grupo y la persona.

La historia colectiva del campesino, debe llevar a un reconocimiento y autoreconocimiento. De esta forma la identidad histórica y el sentido de pertenencia, ayudan a hacer resistencia frente a los múltiples procesos de invasión cultural, y convierte a la cultura en vínculo entre las comunidades en la búsqueda de un posdesarrollo.

Para Max-Neff, las políticas globales niegan lo local movidos por leyes económicas, por esto lo local debe cobrar fuerza:

"Si los sistemas nacionales han aprendido a eludir a los pobres, los pobres tienen que aprender a eludir a los sistemas nacionales... Todo lo que se puede realizar a nivel local debe realizarse a nivel local. Estimo que la vía debe partir desde la aldea, hacia un orden global" (Max-Neef , 1984).

\section{Metodología}

El trabajo realizado es de tipo cualitativo. Ya que intenta hacer una aproximación global de las situaciones sociales para explorarlas, describirlas y comprenderlas de manera inductiva. Interactuando con miembros de un contexto social, compartiendo el significado y el conocimiento que tienen de sí y de su realidad (Triana, 2003). De esta forma, se persiguió analizar y comprender la realidad en la que están inmersas las personas pertenecientes a la comunidad de Toca Boyacá, enmarcadas en los impactos del desarrollo y las implicaciones de éste en la memoria.

Se soportó en un enfoque histórico hermenéutico, teniendo como base la investigación de historia oral, interpretación de vestigios materiales, relatos solicitados y no solicitados, entrevistas etnográficas, entre otras. Así, la realidad social se entendió como un complejo entramado de historias que convergen en los sitios de importancia cultural e histórica, en narraciones orales que están en el imaginario de los pobladores del municipio de Toca.

El trabajo, en su parte de rescate de memoria, se sustentó en el método etnográfico, que se puede definir como: "El estudio descriptivo de la cultura de una comunidad, o de algunos de sus aspectos fundamentales, bajo la perspectiva de comprensión global de la misma" (Aguirre, 1995). Esto permitió un acercamiento a las comunidades se describieron y registrando las características comunes desde lo social y cultural, se entendieron las brechas generacionales, los impactos de las medidas económicas globales, todo esto desde el acercamiento con la comunidad que permite el método etnográfico.

Este método, permitió la participación abierta en la vida cotidiana de las personas, viendo lo que pasaba, escuchando lo que se dice, preguntando cosas. En este sentido, se hizo un acercamiento a la comunidad de Toca, y se obtuvo de su propia voz, de sus relatos orales, de sus imaginarios, componentes de la memoria y la historia del Municipio.

El trabajo con los estudiantes se fundamentó en la Investigación Acción Participativa, en esta parte: "A diferencia de otras metodologías, incluye en el proceso de investigación su por qué y para qué; su sentido y objetivo: la transformación para a un mejoramiento de la calidad; con miras a que una colectividad tenga mayor control y autogestión sobre sí misma" (Alcocer, 1998). De ésta manera, se presentaba a los estudiantes los resultados del rescate de la memoria, tratando de que ellos entraran a ser parte de la investigación. Se conviertieron en protagonistas del proceso, buscando que el grupo de trabajo contribuyera a entender la relación de su historia con el desarrollo y, de esta 
menera, generar conciencia en la toma de desiciones, tendientes a mejorar la relación de identidad cultural del Municipio de la mano del posdesarrollo.

\section{Resultados}

Toca es ejemplo de la usurpación cultural por parte del desarrollo. Medidas como la apertura económica, sometieron al campesino a un proceso de invasión, ya que llevó a importaciones de trigo y cebada a precios bajos, lo que desfalcó la economía productiva del Municipio. El nombre de Toca "La Espiga Dorada de Colombia", pierde sentido, ya que los otrora grandes terrenos de cebada y trigo hoy están ausentes.

En lo que respecta a la reconstrucción de memoria se encontraron fenómenos que marcan la historia del Municipio y en donde se evidencío que gran cantidad de la población no tenía conocimiento de los vestigios históricos, fruto de las invasiones culturales que desde lo económico y productivo, alejan a la población de su realidad.

A continuación se describen la reconstrucción de la memoria que se realizó con los pobladores de Toca, en su mayoría adultos mayores del Municipio; esto se logró a través de entrevistas informales y visitas a los sectores de importancia. Lo que se evidenció en estos lugares e imaginarios, es la desmemoria hecha carne en el olvido de los sitios de importancia cultural y que sirven como base para la identidad cultural.

\section{Resultados del trabajo etnográfico}

\section{Pueblo de piedra}

Registro siete, diario de campo. Agosto primero de 2010. Pueblo de Piedra:

Al escuchar y preguntar en el pueblo, entre tiendas y supermercados me recomiendan que vaya a "Pueblo de piedra", en la vereda Tuaneca Arriba. Me dicen que hay unas piedras grandes, que es un sitio de importancia. Pero nadie da razón de por qué.

Toca fue en la época precolombina un asentamiento indígena. En una expedición del General Juan de San Martín, en 1536 encontraron un caserío de indios dirigidos por el Cacique Tocavita (Alcaldia Toca). Teniendo esto como base se buscaron pistas de vestigios arqueológicos, que mostrarán el origen indígena del Municipio. Es así como empotrada en la vereda Tuaneca, en un sector llamado "Pueblo de Piedra" se encontraron pictogramas y vestigios arqueológicos.

Vale la pena destacar que este sitio está olvidado, no tiene ningún reconocimiento por parte de los pobladores y muy cerca de él, se hacen labores agrícolas afectando con los insumos las pinturas.

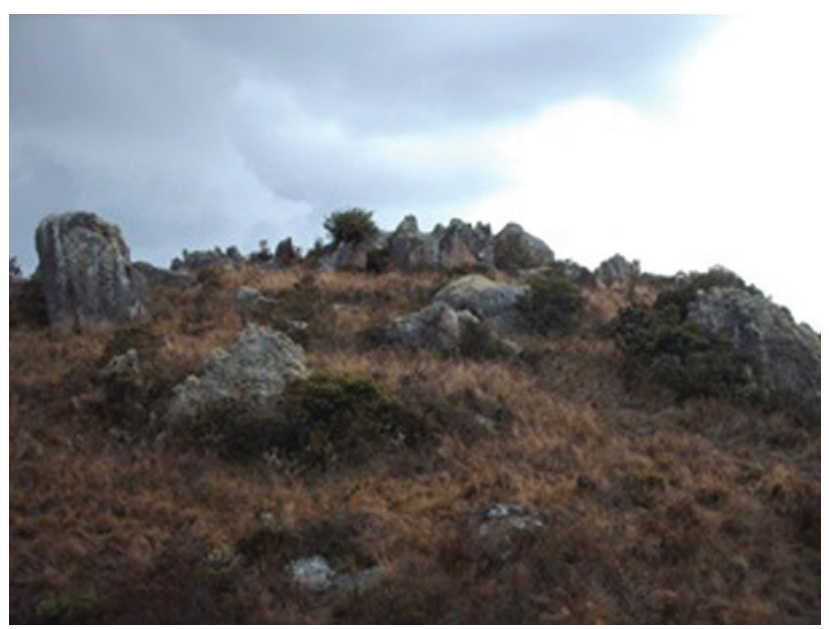

Figura 1: Pueblo Piedra.

\section{Las moyas del recuerdo}

Registro ocho, diario de campo. Agosto 14 de 2010. Hacienda Santa Bárbara.

Con el guía nos trasladamos a la Hacienda Santa Bárbara, según algunas de las pesquisas, allí hay algo que le llaman ollitas, que según su descripción se asemejan a mollas. 
Nehemías un indígena del Cauca nos atiende. Nehemías cuenta que su patrón, le había dicho que de la moya más grande salía una culebra y que apenas salía para meterse en la otra moya y que después salía de otra y así. El guía, Miguel Alba, dice que el agua de las ollitas, la utilizaban los antiguos para curar heridas. Agrega, que cuando alguien se cortaba, le decían que fuera a las ollitas y trajera de esa agua y con esa se lavaban las heridas.

Las moyas son una parte importante de vestigios de los indígenas en todo el altiplano cundiboyacense; sin embargo, desde el eclecticismo, los vestigios indígenas y la idiosincrasia campesina se dan múltiples significados.

Pese a que pocas personas saben de la existencia de las moyas y menos su significado histórico. En la hacienda Santa Barbará se puede encontrar al lado del rio, en una gran piedra, moyas en perfecto estado.

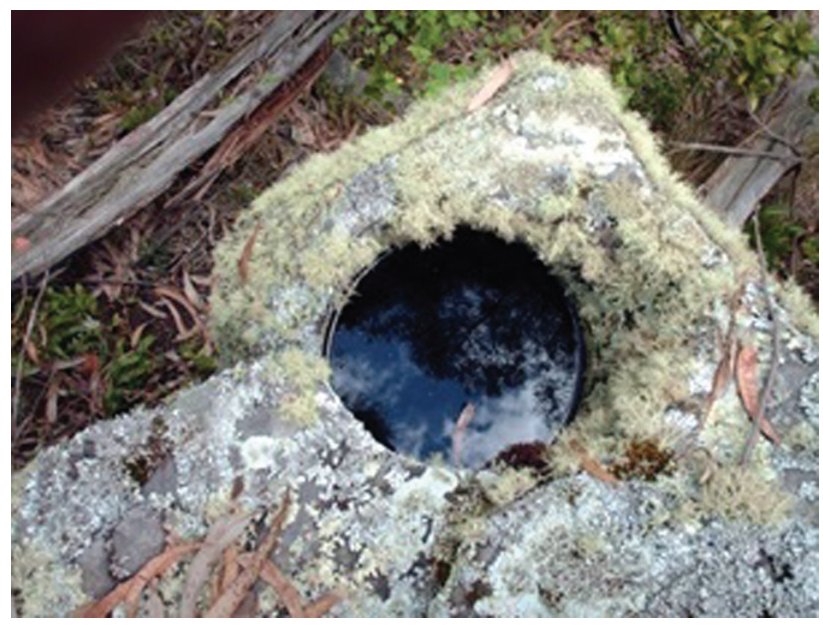

Figura 2: Hacienda Santa Bárbara, Moyas.

\section{Historia de la hacienda Santa Bárbara}

Diario de Campo, registro nueve, charla con Don Pedro trabajador de la Hacienda Santa Bárbara. Agosto 14 de 2010.
Pasando el río que alimenta la gran piedra con las mollas, está la casa de don Pedro un anciano. El saludo es fraternal, don Pedro vive sólo en una pequeña casa y fue empleado de la hacienda, entonces empieza a contar la historia.

Jorge Sánchez Salar era médico, su muerte fue infausta. Conservador de corazón y de vida, su hija bogotana se casó con un liberal. Entonces él, no pudiendo sobrepasar tamaña pena, después de haber enterrado su fortuna, se encerró en uno de los cuartos de la hacienda y se clavó en su anatomía un gran sable que moraba en unas de las paredes.

La historia de las haciendas se remonta a una estructura pseudo-feudalista, donde los campesinos a cambio de un pedazo de tierra, trabajan para el señor hacendado. Las haciendas en Toca, marcaron la historia económica agraria y su descomposición se dio en la época de industrialización cuando los grandes capitales se iban a las ciudades.

El campo como signo de atraso, frente a la ciudad como insignia del futuro, marcaría el inicio del fin de las haciendas. La desintegración de las haciendas iba a dar origen a los minifundios.

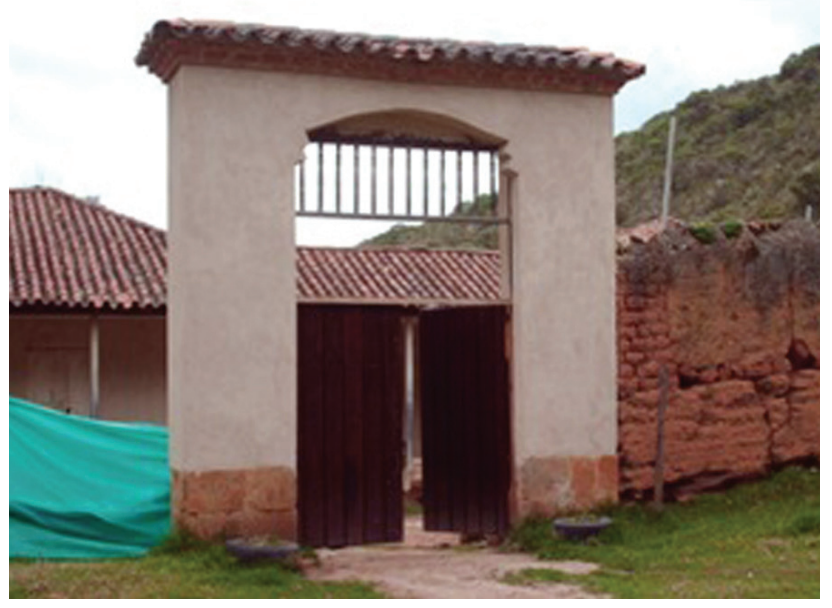

Figura 3: Hacienda Santa Bárbara. 


\section{Hacienda San Pedro}

Diario de Campo. Registro 1, Diálogo con Aurelio Cuidandero, Hacienda San Pedro. Julio 24 de 2010

Don Aurelio, cuidandero de la hacienda San Pedro.

El arribo a la hacienda se hace por la vía principal al pueblo. Hay una entrada enmarcada con dos columnas en ruinas. La hacienda, dice Don Aurelio cuidandero de 80 años, fue de la familia Sánchez, construida desde hace 200 años aproximadamente. Los dueños de la hacienda eran los dueños de toda la vereda del centro de Toca, y sus límites eran las fronteras de las otras haciendas. Liberales ellos de corazón, heredaron a sus trabajadores el color político.

Otra de las haciendas de importancia en Toca, fue la hacienda San Pedro. La arquitectura de las haciendas refleja el olvido. La caída de los muros refleja, el abandono de los herederos, refleja la desmemoria y el presente autista del pueblo, y la evasión de las políticas públicas por buscar la restauración de estos lugares.

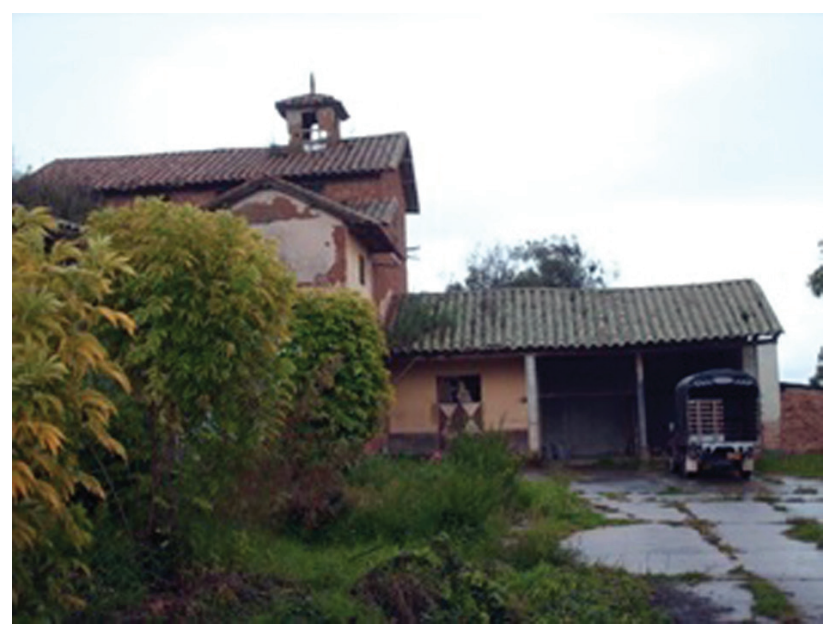

Figura 4: Hacienda San Pedro.

La herencia política, la instauración de un nuevo sistema económico, y la estructura de dominación a la cual han estado sometidos los campesinos, llevan a repensar el desarrollo. Ya que a los campesinos se les ha acallado históricamente su voz, la hacienda y las políticas son ejemplo de esto.

\section{De la lucha entre liberales y conservadores}

Diario de campo, Registro 10. Época de la violencia, Salomón Ochoa (Apodado El Sabio). Fecha: 24 Agosto de 2010

Llegamos a la casa de don Salomón (85 años), nos presentan y comienza su relato.

Don Salomón se declara liberal, según él, el partido era una cuestión de herencia, pues la vereda donde él nació era liberal, San Francisco. La otra vereda liberal era Tuaneca. Estas dos veredas entraban en confrontación los días sábados con las veredas conservadoras, Chorrera y Cunuca, en la Calle Real de toca.

La calle real era la calle principal, en donde estaban centrado todo el comercio de Toca. Son dos cuadras, cada bando tenía una esquina. Los liberales ocupaban la esquina del parque; y los conservadores se hacían parados en la esquina del cementerio.

La Hacienda San Pedro era liberal, por esto las veredas, Tuaneca y San Francisco, que la conformaban, eran de este partido. Por otra parte, las veredas de Cunuca y Chorrera siendo influencia de la hacienda Santa Bárbara, eran conservadoras. El mapa político de Toca se resume en el color político de las haciendas y sus veredas.

Muchas son las historias de este fenómeno político en Toca, pues se convirtió en un espectáculo que generó personajes que casi empezaban a formar leyendas vivientes, por su ferocidad y arrojo en el combate en la calle real. Donde el combate se hacia en medio de chicha y bordones. La "Calle Real" hoy en Toca es una calle más y muchas de las generaciones contemporáneas no reconocen la importancia que jugó esta en la historia como un reflejo de un fenómeno Nacional. 


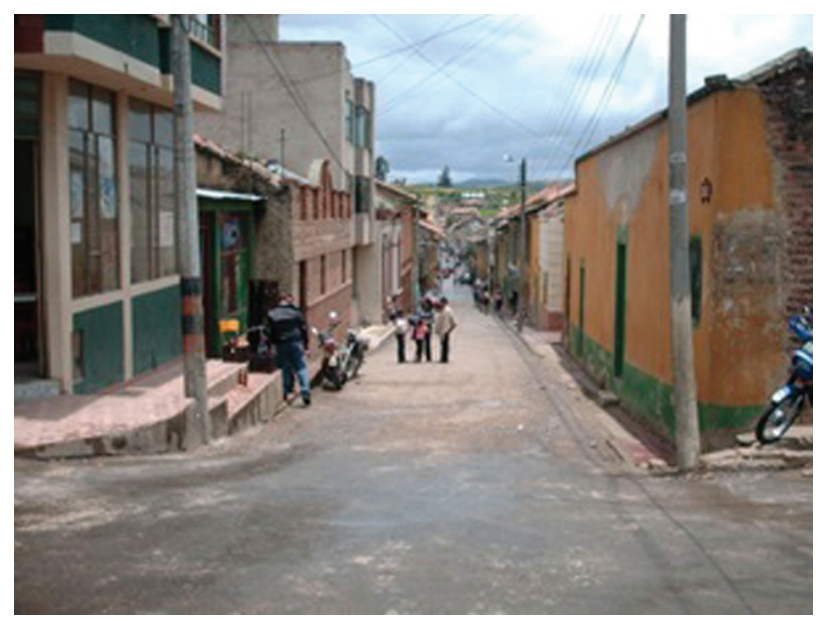

Figura 5: Calle Real.

\section{Las Chicherías}

Diario de Campo, Registro 19, Salomón (El Sabio), 23 de Octubre de 2010.

Desde su mirada picaresca empieza a contar la historia de las chicherías. En 1950, se impone el impuesto a la fábrica de chicha, en el mandato de Laureano Gómez.

Las chichería de don Prospero Galán fue la primera en Toca. En aquel entonces las fábricas de chicha le pagaban al departamento y el impuesto se llamaba ventilla. Esto se da por los efectos de la chicha en la gente, al avivar los sentimientos políticos y ser una mecha para la violencia entre liberales y conservadores.

Desde el impuesto creado la policía empezó a perseguir a las chicherías ilegales, pero después se prohíbe las chicherías y es así como se eleva el consumo de la cerveza. La fábrica de chicha las Uchuvitas fue una de las últimas de Toca.

Las chicherías y su prohibición son una muestra de la invasión cultural a la que se han venido sometiendo los pueblos de Colombia, la implantación de la cerveza como signo de caudal y de poder fue el inicio de la aniquilación de la chicha y el guarapo como forma de autodeterminación en sus formas culturales.
Toca no fue la excepción a esto y entre recuerdos y pesares, se recuerdan la chichería y las burlas a la ley que hacían los campesinos.

\section{La Mona Santos}

Diario de campo. Registro 20, Luis Ochoa, Sobre la tienda de la Mona Santos, Fecha: 30 de octubre de 2010

Nos encontramos y al son de una agüita de hierbas empieza la charla.

En la tienda de la Mona Santos, entraba el que tenía dinero, me cuenta, ella era una persona muy respetable. Su tienda empezó en una esquina del parque, y en ella atendía la mamá, pero después ella compró en el centro del parque donde su fama se extendió.

El nombre de ella era SANTOS JIMENEZ, sólo tenía un apellido, porque nunca fue reconocida por su papá, que aún hoy se mantiene en el anonimato. La tienda de la Mona, dice don Luis, era muy solemne y su carácter no dejaba que los ánimos políticos se levantaran en su tienda.

La tienda de la Mona Santos era el punto neutro del parque central, frente a las confrontaciones que se llevaban a cabo en la calle real, entre liberales y conservadores. La Mona fue una mujer que sobresalió en una época machista, ella con su apariencia fuerte, se enfrentaba a todo aquel que levantara la voz en su tienda o el que pasado de copas empezara una trifulca con alegatos políticos.

Muda, silenciosa y en muchas ocasiones oculta para los ojos de muchos, bajo el busto de Plinio Apuleyo Mendoza, mora la carta que Gabo dirige a Toca. Entre sus túneles de tiempo y suspiros de memoria aparece la figura de la Mona Santos. La recuerda él, como una mujer dueña de la tienda donde se hablaba de política, al ritmo de aguardientes y cervezas. 


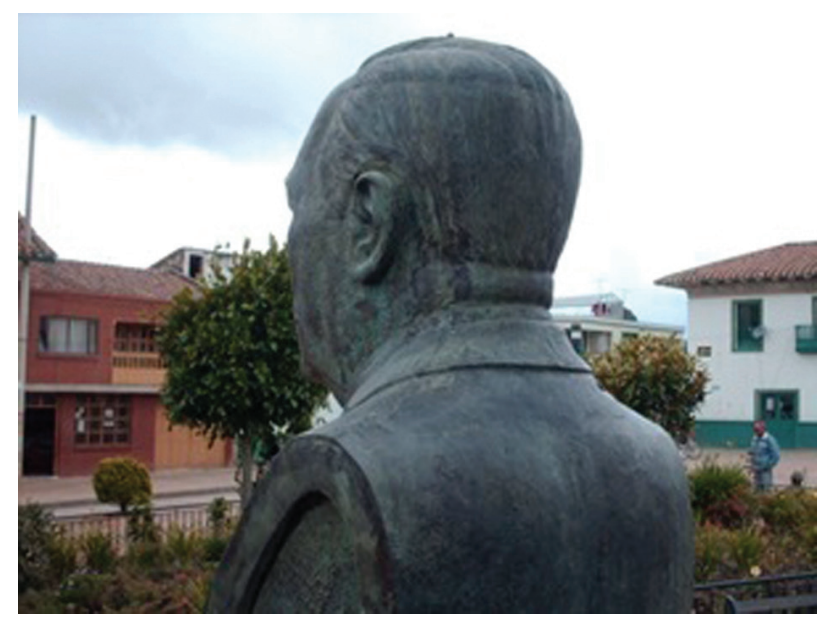

Figura 6: Hacienda San Pedro.

\section{El Cristo despedazado y los Matacristos}

Diario de campo, Registro 20. Salomón Ochoa (Apodado El Sabio). Fecha: 13 de Noviembre de 2010

Se cuenta, dice don Salomón, que corría el año de 1918, y un niño de Tuta tenía un daño en una pierna, la mamá lo llevó a Toca al Santo Cristo. Cuando llegó a la romería hizo una promesa, y al salir de la iglesia, el niño se alentó de su pierna, milagrosamente. Como el fermento, la noticia de las bondades del Santo Cristo creció tanto que empezaron a llegar necesitados de favores de todos los pueblos.

Los Tutences no fueron la excepción, esto ocasionó gran envidia por parte de las otras parroquias y fue así que el Párroco de Tuta de apellido Pineda sube a Toca. No sin razón se sentía desplazado, entonces arremete poseído de la ira contra el Santo Cristo, y con machete en mano destruye la imagen del Señor.

Otros relatos cuentan que el apelativo (Diario de Campo. Registro 9, Miguel Burgos, Fecha 14 de agosto de 2010) surge cuando los Tutences subían a Toca, en grandes peregrinaciones, debido a que la imagen del Cristo de la iglesia sudaba. Con el paso del Tiempo se descubrió que el cura de Toca, untaba todas las noches una delgada capa de parafina a la imagen en el rostro y por la acción de las velas, la parafina se derretía y daba la impresión de la transpiración del Cristo. El cura de Tuta al ver tamaña ofensa y al sentir sus arcas vacías, llegó a Toca y con machete en mano destrozó la imagen. Desde ese entonces a los Tocanos se les llama "Mata Cristos".

\section{Resultados IAP en el Instituto Técnico Agropecuario de Toca}

La propuesta pedagógica se basó en la investigación acción participativa. Este trabajo se realizó durante el segundo semestre de 2009, en el Instituto Técnico Agropecuario de Toca. Las sesiones de trabajo se cimentaron en charlas con los estudiantes y en un "coo" y "auto" descubrimiento de una memoria olvidada.

Mediante la reconstrucción de la memoria hecha a través de la etnografía, iba generando identidad histórica, y descubriendo en el grupo de estudio las falencias históricas del desarrollo, manifestadas en medidas económicas, culturales y tecnológicas que tenían como consecuencia el olvido. De esta forma desde la memoria se fundaban reflexiones sobre nuevas vías para el futuro, como el posdesarrollo.

Los estudiantes iban descubriendo sesión por sesión parte de su memoria y lentamente se convirtieron en investigadores. Para el grado sexto los niños y niñas, empezaron a indagar con sus abuelos y padres historias, que generalmente tenían que ver con su vereda. Así, sesión por sesión se iban compartiendo el material etnográfico y los encuentros de los estudiantes con su pasado. Generalmente estos relatos tenían que ver con tesoros y espantos.

Por su parte, en el grado once algunos estudiantes después de charlas y de compartir el material fotográfico recolectado, algunos estudiantes empezaron a reconstruir su pasado $\mathrm{y}$, se encontraron con su identidad. Un ejemplo de esto fueron las salidas que se desarrollaron 
en conjunto en busca de conocimientos sobre sitios que habían escuchado. De esta manera, se tomaron registro de moyas, sitios de importancia arqueológica como casas en bareque y sitios de importancia ecológica como la caída de agua el "Chorro de la Vieja".

Diario de Campo, registro 15. Casa de bareque, Octubre 2 de 2010

Por el camino que lleva a Pesca, nos encontramos con Fredy y Elkin dos de los alumnos de grado once que me manifestó el conocimiento de una casa "de la de los antiguos" con techo de paja y muros de barro y bareque.

Voy en un camión, y los recogemos en el punto de las oyitas. Se montan y emprendemos el camino, recorremos ahora una variante que va a la vereda de Chorrera y después de menos de 10 minutos hacen parar el carro.

Me menciona que ya estamos cerca y empezamos a caminar, recorremos unos metros, atravesamos una cuantas cerca de alambre de púa, y frente a un pequeño árbol, la casa de bareque se detiene en el tiempo, para impedir que su memoria caiga en ruinas.

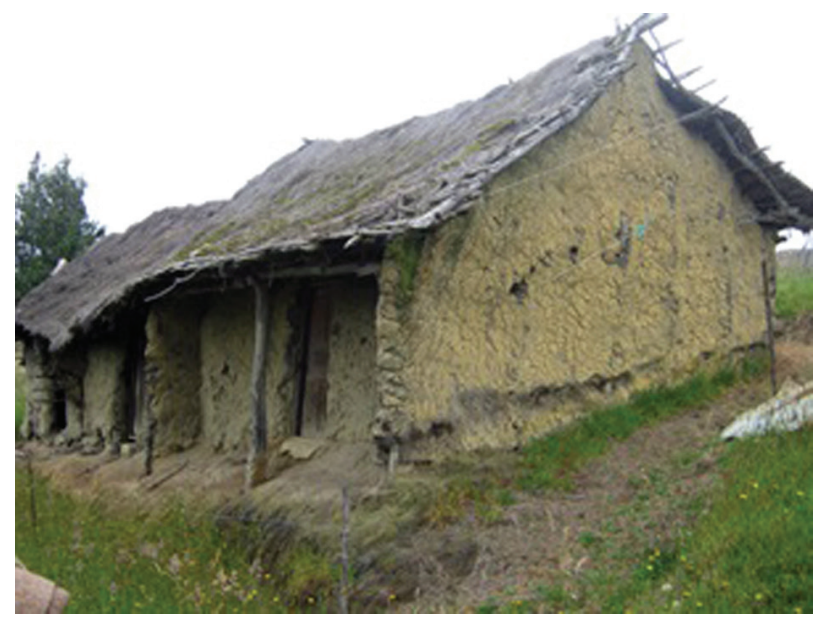

Figura 7: Casa de bareque.

Es muy raro encontrarse de frente con el pasado, hecho carne en la arquitectura, la paja pinta la parte superior de la casa, una paja entrada en años. El techo esta ondulado, curvado, como se corva la espalda de un campesino cuando trabaja, cuando los años hacen estragos.

Está dividida en tres partes, la primera y la segunda son cuartos, y última es la cocina, pintada con el tizne de muchos años y bocas que fueron alimentadas.

Al tiempo llega don Roberto, uno de los vecinos de la casa y empieza a contar aspectos claves que a los ojos de cualquiera quedarían cortos.

Diario de Campo, registro 16. Casa de bareque, Octubre 2 de 2010

Seguimos el camino, y aproximadamente a media hora después entrar en un pequeño resquicio de bosque por una hora llegamos cerca del rio Chorrera, en una gran piedra moran espectadoras del paso y del tiempo las moyas, incrustadas en una gran piedra.

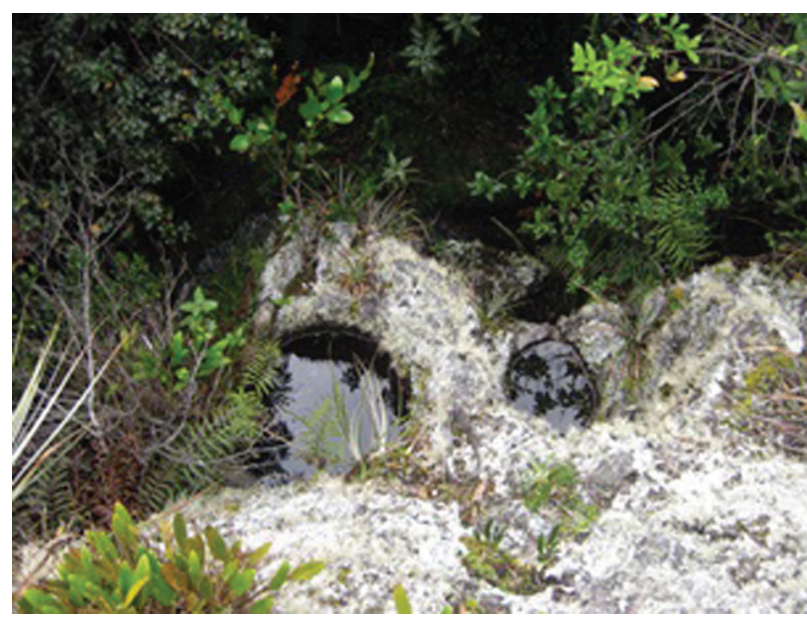

Figura 8: Moyas.

Mi sorpresa es innegable, subo a la piedra y tomo registro fotográfico. Elkin observa, pero su admiración por este sitio ahora es diferente, sube conmigo a la roca y ambos desde arriba la contemplamos. Es un encuentro con el pasado más remoto de Toca, un encuentro con los asentamientos indígenas. 
Durante el trabajo los estudiantes de once y sexto grado, se encontraron con su memoria colectiva, primero teniendo como soporte el trabajo etnográfico realizado con los pobladores de Toca y presentado en el aula de clase; en segundo momento del encuentro se dio en el trabajo investigativo que se realizó, de la mano con los abuelos y padres de cada estudiante. De la misma forma, las salidas investigativas con estudiantes fue el punto máximo del trabajo.

\section{Discusión de resultados}

A lo largo de dos años de trabajo, recorriendo calles y entrevistando a la gente, se pudo evidenciar la presencia de un presente autista, en donde el pasado ha perdido significado. Esto se da desde las profundas invasiones a las que se han sometido los sectores rurales, en este caso el municipio de Toca. El desarrollo rural, ha seguido las sendas del desarrollo economicista, se han implantado las decisiones globales y negado la capacidad de decisión de lo local.

En este sentido, procesos históricos como las haciendas, la industrialización, la apertura económica y en este último tiempo, la empresarización del campo, desconocen la cultura de lo rural y la ven como una forma de atraso. Así las culturas rurales, menospreciadas y ultrajadas, y concebidas como bastiones en contra del desarrollo sometidas al escarnio. De esta forma, las nuevas generaciones no encuentran ningún sentido en el pasado, ya que no tendría sentido encontrarme en la memoria, para generar identidad, si esto es atraso y algo despreciable.

En el trabajo etnográfico los adultos con edades entre 35 y 50 años, desconocían en su mayoría la historia de su Municipio. Para el caso de los adultos mayores, se podía evidenciar cercanía con los acontecimientos históricos vividos, pero no daban cuento de los sitios de vestigios indígenas. Por último, en el caso de los jóvenes del Co- legio Técnico Agropecuario, el desconocimiento por la historia era total, salvo sitios cercanos a donde ellos vivían.

A lo largo de los días de trabajo la propuesta pedagógica fue tomando forma. La metodología consistía en presentar a los jóvenes de grado once y niños de sexto, los avances que se iban tejiendo en el trabajo etnográfico, a través de fotos y videos. Así se trataba de mostrar la historia del Municipio y sobre todo seducir, para que los estudiantes se convirtieran en rescatadores y constructores de su propia historia.

Con el paso de los días y de la mano con los resultados de la etnografía, los estudiantes se convirtieron en investigadores y con las salidas y entrevistas con sus abuelos, empezaron a realizar caminatas de reconocimiento y registros sobre su memoria. Esto llevó a que los estudiantes se contemplaran como parte de su pueblo, y reconocieran la historia, y como esta en la mayoría de los casos, no ha sido decidida por ellos.

El desarrollo se tornó de esta manera, susceptible a críticas, y se abrió un camino donde la cultura, desde la memoria, creó vínculos de identidad, con miras de generar nuevas formas de concebirlo.

\section{Conclusiones}

Desde la literatura citada se pudo referenciar como el concepto del "Desarrollo" ha tenido serias falencias en sus objetivos de reducción de la pobreza, pero ha sido muy útil en las relaciones de países hegemónicos con los países en vía de desarrollo, implantando medidas políticas y económicas en el orden local, imponiendo una relación asimétrica en donde lo local es subyugado por lo global.

El posdesarrollo se abre como una manera distinta de concebir el desarrollo, para esto lo local y la cultura juegan un papel importante. Sin embargo, desde las múltiples invasiones culturales existen 
procesos de erosión de la memoria. La memoria se mostró en este trabajo, como fenómeno que alumbra la identidad en procesos de fortalecimiento de lo local, esto se evidenció desde la propuesta pedagógica. Lo que generó se presentó a los jóvenes estudiantes.

El trabajo etnográfico desde entrevistas, observaciones, vivencias y convivencias con adultos mayores del municipio de Toca, develaron aspectos como cuentos folclóricos, leyendas e imaginarios relacionados con los sitios de importancia cultural; estos fueron un pilar fundamental en la construcción de la propuesta pedagógica, generando sentido de identidad en jóvenes del Instituto Técnico Agropecuario del municipio de Toca.

El rescate de memoria del municipio de Toca, generó reconocimiento y herramientas para la propuesta pedagógica, esta se baso en sitios con vestigios de la cultura indígena, historias de las haciendas y sus implicaciones en la conformación política del municipio hoy. De la misma, manera se recopilaron relatos de personajes iconos de la memoria Tocana e historias de calles importantes en la época de la violencia, así como algunos cuentos folclóricos.

La metodología en el aula encaminada desde la investigación acción participativa, convirtió a los estudiantes Tocanos en escritores de su propia memoria, generando procesos críticos frente a su historia y cimentando nuevas formas de ver su futuro, apartándose de un desarrollo vertical y entendiendo el concepto del posdesarrollo como una construcción horizontal, donde lo local iluminado desde la memoria es capaz de construir procesos para su futuro.
Este trabajo reconoce sus limitaciones: no obstante, se puede concluir que desde la teoría se hace un gran aporte crítico frente al desarrollo, mostrando salidas tanto teóricas como una senda hacia la practicidad desde lo local.

\section{Literatura citada}

1. Aguirre, Á. (1995). Etnografía. Metodología cualitativa en la investigación sociocultural. Bogotá: Alfaomega. p. 3

2. Alcaldia Toca. (s.f.). Toca, Nuestro municipio. Recuperado de: http://www.toca-boyaca.gov.co/index.shtml

3. Alcocer, M. (1998). Investigación Acción Participativa. En E. J. Galindo, Técnicas de investigación en sociedad, cultura y comunicación (pág. 439). Mexico: Parson. p. 439.

4. Chávez, T. (2010). Tiempo y espacio, territorio y memoria (reflexiones desde la antropología). Revista Universidad de Sonora . p. 25.

5. Degreiff, A.(Diciembre de 2005). Lo que no sabemos sobre el intercambio tecno-científico entre sur y norte: norte-centrismo, difusión científica y estudios sociales de la ciencia. En Revista de Estudios Sociales.Revista No 22 .p. 59.

6. Escobar, A. (1996). La invención del tercer mundo. Bogota: Grupo Editorial Norma. p. 70, 279, 11.

7. Fontana, J. (2006). ¿Para qué sirve la historia en tiempos de crisis? Bogota: Ediciones pensamiento Critica Colección mundo sin fronteras. p. 182

8. Forero, J. (2010). Economía campesina, pobreza, tierra y desplazamiento en Colombia. En J. FORERO, El campesino colombiano (pág. 10). Bogota: Pontificia Universidad Javeriana.

9. Machado, A. (2001). El modelo de desarrollo agrícola. En Apuntes del CENES. vol 20. No 31-32. p. 202.

10. Max-Neef, M. (1997). Desarrollo a Escala Humana: Una opción para el futuro. Medellín.: CEPAUR Fundación. Proyecto 20 editores. p. 110, 19, 20, 16

11. Max-Neef, M. (1984). La economía descalza. Montevideo: Editorial Nordan-CEPAUR. 135, 196.

12. Triana, A. (2003). Sentido y cultura. Realidad de la Escuela Rural. Tunja: Publicaciones UPTC. p. 17. 